\title{
Optimization of a perishable inventory system: A simulation study in a Ho.Re.Ca. company
}

\author{
Elena Piva ${ }^{1}$, Letizia Tebaldi ${ }^{2}$, Giuseppe Vignali ${ }^{2}$ and Eleonora Bottani ${ }^{2}{ }^{*}$ \\ ${ }^{1}$ Logistics and Procurement Office, CIRFOOD, Via Nobel 19, 42124, Reggio Emilia, Italy \\ ${ }^{2}$ Department of Engineering and Architecture, University of Parma, Viale delle Scienze 181/A, 43124, Parma, Italy \\ ${ }^{*}$ Corresponding author. Email address: eleonora.bottani@unipr.it
}

\begin{abstract}
The main goal of this paper is to describe the optimization of the inventory management process in a real context of perishable food products. The study involves one of the largest Italian HO.RE.CA. companies, located in the north of Italy and operating as a provider of the catering, commercial and welfare services. A simulation model was set up with the purpose of adapting three traditional reordering policies (i.e. Re-Order Point, Re-Order Cycle, and $(\mathrm{s}, \mathrm{S})$ ) to a set of products belonging to company's assortment and evaluating the resulting economic outcomes. To this end, each policy was modelled on Microsoft Excel ${ }^{\mathrm{TM}}$, so as to compute the total cost of inventory management and determine of the minimum cost strategy. A comparison with the current company's performance and that achievable with the optimized policy is also proposed.
\end{abstract}

Keywords: Inventory management; Perishable items; Simulation model; Reorder policies

\section{Introduction}

If the correct answer for the questions when and how much to order existed, the keyword "inventory management" would probably not return over 7,000 results on Scopus database. Indeed, this outcome confirms that the stock management is a key question for companies, much debated in the academic world.

Stocks are defined by Waters (2003) as "all the goods and materials that are stored by an organization; a store of items that is kept for future use". According to Arnold (1991), five different types of stocks can be found within a warehouse: raw material stocks, work in progress (WIP) products, finished items, distribution stocks and maintenance, repair and operational supplies (MROS). Again, according to their usage and role in the production process, Balestri (2009) proposes another classification, which includes the subdivision into existing stock, virtual stock, normal stock, maximum stock, safety stock and speculative stock. Overall, the general peculiarity is that of decoupling purchases and sales, since these activities operate at varying paces due to the market volubility. Stocks are considered the most difficult asset to be managed for firms, and this is also supported by the fact that their economic value impacts for $20-60 \%$ of the whole set of company resources (Kolias et al., 2011). It follows their relevance on the performance not only of organizations, but of the whole supply chains these last belong to (Shapiro and Wagner, 2009).

Among the main problems related to the inventory management, the huge capital investments for purchasing goods are included, together with their storage within warehouses, which involves costs for lighting, cooling/heating, handling, equipment depreciation and personnel remuneration; moreover, possible risks due to obsolescence, damage or deterioration according to the products in question must be taken into account. On the other hand, stocks

(C) 2020 The Authors. This article is an open access article distributed under the terms and conditions of the Creative Commons Attribution (CC BY-NC-ND) license (https://creativecommons.org/licenses/by-nc-nd/4.0/). 
are vital for an organization, as they allow to avoid the stock shortage situation, occurring when it is not possible to cope with market demand and, consequently, losses arise.

To deal with this issue, several initiatives were developed (Alrjoub \& Ahmad, 2017) all aiming at determining an optimal level of stocks allowing to flexibly meet the variable market needs, simultaneously minimizing operating costs. For instance, it is worth mentioning the implementation of appropriate supply chain software (Blankley et al., 2008), collaboration among the actors, which returns techniques such as quick response and vendormanaged inventory (VMI) (Waller et al., 1999) or justin-time (JIT) inventory management practices (Schwarz \& Weng, 2000). Several benefits were achieved through the adoption of such strategies, e.g. reduction of operating and capital costs, key performance indicators improvement, material flow coordination, reduced lead time and consequently a better customer service, more flexibility in facing changing conditions.

Over the past years, several models were also developed to support the inventory management. The first proposed goes back to 1913 (Harris, 1913), the renowned Economic Order Quantity (EOQ in the following referred as Re-Order Point policy) which provides an exact procedure to determine the optimal quantity of a product to be purchased when dealing with deterministic lot sizing. Starting from here there is a plethora of pertinent studies; Silver (1981) classified them through several factors as grouping criteria, i.e. the number and storage locations, number of products, time frame, demand and lead time, continuous/batch supply. What these models have in common, is the assumption that items can be stored for an indefinite period; but unfortunately, this not happens for every product. Indeed, some items, can be damaged or become obsolete (Goyal and Giri, 2001), and this is exactly the case of perishable goods such as food, including fruit, vegetables and many others and beverages.

This fact generated a niche segment of the main topic of inventory management, namely the inventory management specifically for perishable products. Several models are dedicated to this specific issue, which will be discussed in the following section. This particular class of products deserves attention as they can be sold only for a limited time due to their shelflife; after the expiry date they must be withdrawn from the market, generating both monetary loss and at the same time disposal costs. It follows that optimization, efficiency and accuracy are essential in this segment.

In the light of this, the aim if of this paper is to present the simulation of three different re-order policies, namely the Re-Order Point, the Re-Order Cycle and the $(\mathrm{s}, \mathrm{S})$, applied to some selected products of a Company based in the North of Italy, called CIRFOOD, which supplies food and beverages for the
Ho.Re.CA. channel. Indeed, it was demonstrated that simulation models are useful for analyzing issues related to inventory management, logistics and supply chain design (Bottani et al., 2014); accordingly, a model under Microsoft Excel ${ }^{\mathrm{TM}}$ was developed ad hoc for each policy. For selecting items whose behavior had to be simulated, an $A B C$ analysis was carried out as a function of the shelf-life.

The remainder of the paper is as follows: section 2 deals with a brief analysis of literature concerning the main inventory management strategies for perishable products, as well as relating methodological approached. Section 3 details the context of this study. Section 4 is dedicated to the development of the models and to the simulation study, whose results are then discussed in section 5 together with conclusions and further research activities.

\section{Literature Analysis: Inventory Management for Perishable Products}

The role of inventory management in matching supply and demand and getting the right product in the right place at the right time is relevant in any context. However, such role is crucial when managing perishable products (Deniz et al., 2004). Inventory management of perishables items differs from the management of traditional non-perishable ones in that for perishable items, there is a limited time period during which the product can be sold or consumed with profit, which reflects their shelf-life (Wang and $\mathrm{Li}$, 2012). Indeed, the economic value of perishable products deteriorates significantly over time (Blackburn \& Scudder, 2009), which causes additional costs of shrinkage, spoilage or obsolescence (Deniz et al., 2004). Correctly managing the inventory level and the reorder process of perishable products therefore has a direct impact on a company's profitability, as it affects product sales, price, inventory holding cost, spoilage cost, deterioration risk, and on-shelf availability (Chaudhary et al., 2018).

Managers, academics and researchers are putting efforts in understanding and modelling inventory management of perishable items, taking into account the different factors that affect this process, such as product characteristics, level of competition, internal/external constraints, impact of price on demand, product availability, demand type and characteristics, etc. Also, the specific context should be taken into account: perishable products include a series of different items (e.g. vegetables or fruits, baked goods, bread, milk, meat, seafood, blood, radioactive/chemical materials, pharmaceuticals items, Christmas trees, fashion apparels or high-tech products), but the way these products need to be managed can vary considerably depending on the kind of product under evaluation. This is why many models have been proposed in literature for analyzing the inventory management of perishable items depending on the specific environment (Chaudhary et al., 2018). 
Research related to inventory management of perishable items is wide and has recently been reviewed by Chaudhary et al. (2018). As reported by these authors, inventory models for perishable goods started being studied for the specific case of fashion items, which in fact can be considered as perishable as their sales volume decreases significantly at the end of a season (Whitin, 1957). Looking at inventory management for perishable food products, which forms the focus of this paper, the typical approach followed by researchers is to adapt the parameters of the traditional inventory policies to those products. The goal of the analysis is to determine the optimal configuration of reorder policies or on their costoptimality taking into account the characteristics of the perishable products. This implies that shelf-life constraints cannot be neglected; in line with this, the first study targeting perishable food products (i.e. Ghare \& Schrader 1963) modelled the consumption of these items as a negative exponential function of time, so as to take into account their residual shelf-life. Alternatively, the product value or chance of being purchased can be modelled as a function of the residual shelf-life (e.g., Wang \& Li, 2012). Also, products have been be modelled as fixed lifetime items (i.e. with deterministic shelf-life) or as random lifetime ones (i.e. with variable, time-dependent, deterioration rate) (Chaudhary et al., 2018).

As far as the reorder policies are concerned, the traditional policies all have been adapted to the case of perishable products. For the $(\mathrm{S}, \mathrm{s})$ policy, examples of studies on food products have been by Schneider \& Ringuest (1990), and Silver et al. (2009). Ferguson et al. (2007) and Goyal (1985) have instead worked on the Re-Order Point and the Re-Order Cycle policies, respectively. Some studies for the continuous review perishable inventory models are Weiss (1980), Schmidt \& Nahmias (1985), Ravichandran (1995) and Liu and Lian (1999). Bottani et al. (2014) have modelled the reorder process of five food products and tried to adapt three typical inventory management policies to those products. There are also review studies dealing with the problem of inventory control for perishable products, namely Nahmias (1982), Raafat (1991), Goyal \& Giri (2001) or Chaudhary et al. (2018). A common characteristic of studies that apply these policies to perishable products is that cost optimization models need to take into account additional expenses, associated with the process of removing the obsolete or expired products from the shelf and disposing them (Rajan et al., 1992).

As an alternative to analytic models, simulation approaches have recently appeared as useful tools for studying the behavior of multi-echelon inventory systems (e.g. Wang et al., 2011; Van Der Vorst, 2000; Yu \& Nagurney, 2013). Moreover, several authors have demonstrated that simulation can be used as a powerful tool to analyze specific issues related to inventory management, logistics and supply chain design (Iannone et al., 2007; Longo \& Mirabelli, 2008; Bottani
\& Montanari, 2010; Bottani et al., 2012). The reason for adopting simulation is that, in many practical cases, the definition of exact analytic models for inventory control could be a complex task, especially when numerous factors, such as inventories, lead time, tactical elements or uncertainties should be taken into account (Pirard et al., 2011).

\section{The Context}

The context in which this study was carried out is the Ho.Re.Ca. field, and in particular the CIRFOOD company. Since the '70s, CIRFOOD is one of the most relevant Italian companies operating in collective catering field, catering trade and in providing corporate welfare services. In 2019, more than a hundred million meals were served by CIRFOOD, within a market which has to observe stringent specifications: high quality raw materials required, variety of choice, safety in food conservation, product traceability, ontime deliveries. Moreover, within the collective catering field, several constraints occur in the selection of suppliers and raw materials, which quite often are bound by procurement contracts primarily involving biological or certified PDO, PGI, TSG, fair trade, short chain or km o products; this last list of items represents approximatively the $23.5 \%$ of the total goods managed by CIRFOOD itself.

From an operational point of view, orders can be modified until the day before the scheduled delivery; therefore, the supply system has to be responsive and ready to react to sudden or changed requests from the served structures. The key for being flexible and responsive is an appropriate supply network structure, as that shown in figure 1.

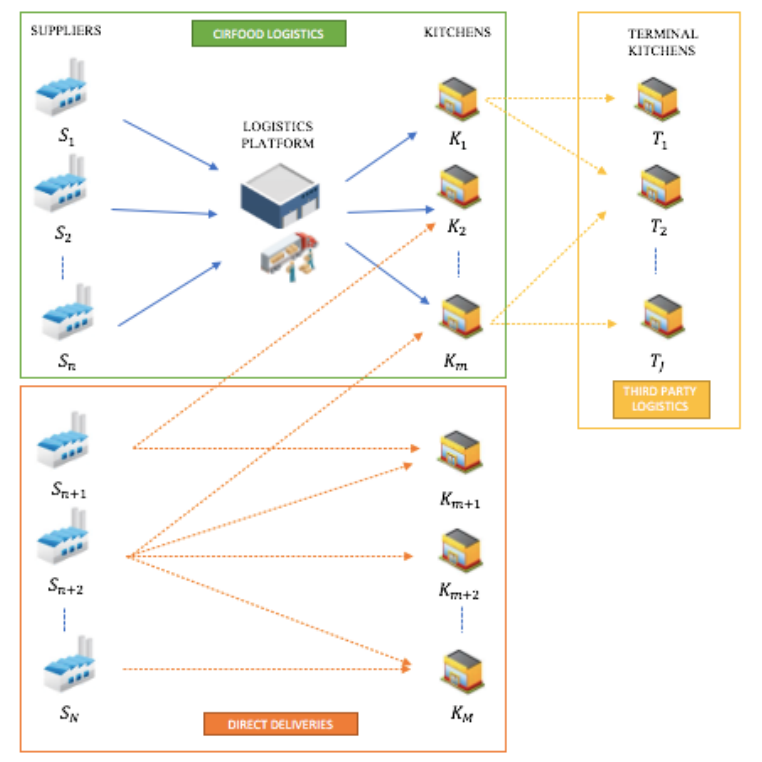

Figure 1. CIRFOOD supply chain.

The project that CIRFOOD is carrying out fits within the green square, the heart of the logistics system; indeed, with a special attention to a sustainability 
perspective, it avails itself of an external centralized platform managed by a third party located in the Emilia Romagna region, cradle of the renowned food valley, which acts as transit point between the different suppliers and customers and hosts the different food products to be delivered. Specifically, these activities are managed by the GEMP office (Italian acronym which stands for raw material management) of CIRFOOD.

The joint aim of this third party and CIRFOOD is to identify the correct trade off which allows to minimize the stocks within their warehouses, while at the same time to ensure an adequate service level for kitchens. This requirement is further complicated by the fact that the overall stock managed by CIRFOOD consists of approximately 1,500 items. Some of these items have shelf-life constraints (shelf-life can vary from 6 to 999 days); other ones, such as wine, salt and many other do not have a limited time in which they can be consumed. Procurement contracts force CIRFOOD to deal with supplies which comply with quality specifications and specific brands. Figure 2 shows the shelf-life trend depending on the product group.



Figure 2. Shelf-life distribution according to the product groups.

Because of the presence of food products with shelflife constraints, the policies used for inventory management necessarily have to take into account the specific characteristics of the products handled and should possibly depending on the group of items considered. To this end, two groups of items are taken into account in the present study:

- Frozen and dry products. Around the $69 \%$ of the items stored belongs to this first class $(43 \%$ and $26 \%$, respectively). Pasta, rice, sauces, fish and frozen vegetables are examples of these products, for which the shelf-life is not a problem. Indeed, for a dry food it is 365 days on average, while for frozen food 270 days; according to that the risk of waste is very low, and safety stocks allowing to respond to the demands can be kept. Only for $8.7 \%$ of products, a Material Requirements Planning (MRP) system is used to schedule purchasing orders, supported by forecasts made according to historical data and expected trends. This planning is a time-consuming activity, as data are manually extrapolated and elaborated on a
Microsoft Excel $^{\mathrm{TM}}$ spreadsheet, which can be prone to errors. Moreover, in the food context historical data are not always reliable, since menus can change, special events can occur, new contracts can be stipulated.

- Fresh and perishable products. This group includes $31 \%$ of products $(21 \%$ and $9 \%$ respectively for the two subgroups). Milk, cheese, yogurt and fresh meat are included, whose shelf-life forces a completely different reorder policy. Fresh products can last around 40 days, while for perishable items this time halves. For these products, the aim is to avoid deterioration, and this is why they are currently managed on a just-in-time (JIT) basis. However, several factors make this approach inefficient. For instance, quantities are frequently not respected, as well as the delivery date and the residual shelf-life agreed. Moreover, within this class, the shelf-life itself can significantly change among products of this category: for instance, some dairy products (e.g. ricotta and stracchino) can last from 7 to 15 days, eggs and yogurt until 35 , while puddings and dessert up to 35 days. These last products could therefore be managed in a different way, and in particular by keeping a safety stock within the warehouse. However, until now differences among products of the same category have not been taken into account, meaning that all the products are treated using the same JIT policy.

The considerations at the end of the above descriptions, together with an increasing market complexity and amount of data to be managed due to a business expansion, encouraged CIRFOOD, which is known as being one of the best companies operating in its field to consider the implementation of an intelligent software for efficiently supporting their inventory management processes. More precisely, the intelligent software should be supported by machine learning algorithms, whose application allows for forecasting the demand of each product, and therefore for making a reorder proposal (on the basis of the available stock) compliant with the shelf-life and reorder constraints imposed. The expected result is to minimize three different key performance indicators (KPI), i.e.:

1. The absolute difference between the in stock and the safety stock for each product;

2. The fixed capital in the warehouse;

3. The number of suppliers arriving at the physical platform.

\section{The Model and Simulation Study}

\subsection{Overview of the reorder policies}

A simulation analysis of three different and 
traditional re-order policies was carried out, with the purpose of identifying the logic behind the development of the intelligent software. As already pointed out in the introduction section, the policies in question are the Re-Order Point, the Re-Order Cycle and the $(s, S)$.

Specifically, the model will simulate the reorder process and inventory amount according to the demand forecast and the expected orders which will be issued when applying the different policies. The ultimate aim is to identify the most appropriate policy for a food product with shelf-life specifications.

In developing the model, the following assumptions were made:

- Each model is used to reproduce the reorder process of a single product;

- The simulative timeframe is expressed in working days;

- The lead time is known and deterministic;

- The delivered quantity is equal to the ordered quantity (i.e., no backorders);

- Stock-out and deterioration are not allowed;

- The average value (eq. (1)) and the standard deviation (eq. (2)) of the daily demand of each single product is computed for the next 25 days starting from the $t$ reference time; the following formulae are involved:

$$
\begin{aligned}
& \mu_{(t, t+25)}=\frac{1}{25} \sum_{i=t+1}^{t+25} d_{i} \\
& \sigma_{(t, t+25)}^{2}=\frac{1}{25} \sum_{i=t+1}^{t+25}\left(d_{i}-\mu_{(t, t+25)}\right)^{2}
\end{aligned}
$$

- The initial stock value corresponds to the stock level at the end of the previous time period.

According to the different policies, the reorder process is triggered by a specific event, according to the description below.

- Re-Order Point: at any time $t$, the system checks the available stock $G_{t}$; in case the stock is found to be lower than the order point set $\left(G_{t} \leq O P_{t}\right)$, an order $O_{t}$ is generated to the supplier. Contrary to $O P_{t}$, the ordered quantity is fixed and can be computed using eq. (3).

$O P_{t}=S S_{t}+L T \cdot \mu_{(t, t+25)}=k \sqrt{L T \cdot \sigma_{(t, t+25)}^{2}}+L T \cdot \mu_{(t, t+25)}$

- Re-Order Cycle: in this case the check on the available stock $G_{t}$ is made at regular time intervals TR; at each interval, an order for the quantity $O_{t}=O U T L_{t}-G_{t}$ is generated. It follows that $O_{t}$ has a variable size, which depends on the target stock $\left(O U T L_{t}\right.$, whose computation is provided in eq. (4)).

OUTL $_{t}=k \sqrt{(L T+T R) \cdot \sigma_{(t, t+25)}^{2}}+(L T+T R) \cdot \mu_{(t, t+25)}$

- $\quad(s, S)$ : also in this case the check on $G_{t}$ takes place at regular time intervals TR. In case the available stock is found to be lower than the Re-Order Point (i.e. $G_{t} \leq s_{t}$ ), an order will be issued. The quantity ordered is $O_{t}=S_{t}-G_{t}$, where $S_{t}$ is the order-up-to level. It follows that in this case as well $O_{t}$ has a variable size.

Moreover, for each policy the following transition equations for the theoretical stock (eq.5) and the stock on hand (eq.6) at time $t$ are applied:

$$
\begin{aligned}
& G_{t}=G_{t-1}+O_{t-1}-d_{t-1} \\
& G_{\text {on hand, } t}=G_{\text {on hand, } t-1}+O_{t-L T}-d_{t-1}
\end{aligned}
$$

\subsection{Objective function}

The ultimate purpose of this simulation study is to identify the policy that allows the total cost of inventory management to be minimized, at the same time meeting the constraints and assumptions of the model. According to that, the objective function consists of the sum of five different cost components, reflecting the costs CIRFOOD incurs in during the whole reorder process. These cost components are detailed below.

1) Order cost, $C_{o}$. This first component depends on the unitary cost of each order and on the number of orders issued during the simulation period $\left(N_{\text {orders }}\right)$. Eq.7 allows to compute this value.

$C_{o}=c_{o} N_{\text {orders }}=c_{o} \sum_{t=1}^{N_{\text {days }}} n_{t}$

2) Logistics cost, $C_{l}$. This cost includes the whole set of activities involved for receiving, handling and distribution. It strictly depends on the quantities passing the platform. The formula is below provided (eq. 8).

$C_{l}=c_{l} \sum_{t=1}^{N_{\text {days }}} O_{t}$

3) Storage cost, $C_{h}$. This value as well depends on the quantities that are stored in the warehouse and on $p_{c}$. Specifically, $p_{c}$ is given by the purchasing cost and the logistics cost, which clearly is in function of the economic value. In this study, a weighted average logistics cost is considered, and it is not affected by the time that products are stored (it follows that $h=0$, in line with the aim of minimizing the economic fixed value). Eq.9 allows to determinate this cost.

$C_{h}=c_{h} \sum_{t=1}^{N_{\text {days }}} G_{\text {on hand }, t}=h p_{c} \sum_{t=1}^{N_{\text {days }}} G_{\text {on hand }, t}$

(9)

4) Stock-out cost, $C_{s o}$. This cost occurs when a specific product is requested, but it is not in stock. It therefore involves a sale loss, a disservice and sometimes even a penalty fee 
and additional work for correcting the orders placed in the system. The relating formula is below shown (eq.10).

$$
C_{s o}=c_{s o} \sum_{t=1}^{N_{\text {days }}}\left(d_{t}-G_{\text {on hand }, t}\right)
$$

5) Disposal costs, $C_{\text {dis }}$. In case the product stored perishes, this cost incurs for the disposal. The formula corresponds to eq.11.

$$
C_{\text {dis }}=c_{\text {dis }} \sum_{t=1}^{N_{\text {days }}} q_{\text {dis }, t}=\left(p+p_{c}+c_{l}\right) \sum_{t=1}^{N_{\text {days }}} q_{\text {dis }, t}
$$

The single components respectively refer to the purchasing cost, the sale loss and the logistic cost, which has been already paid (although it is nullified because of expiration) for receiving, handling and storing the product.

Note that despite stock-out and deterioration are not allowed, their cost item has been included in the model for controlling the compliance with the assumptions.

\subsection{Model constraints}

Constraints to be observed when applying the reorder policy are the following:

- Reorder constraints: problem constraints are lot the size (minimum and maximum) for each product, the re-order quantity (minimum and maximum) which is imposed by each supplier, the delivery lead time, the TR.

- Shelf-life constraint: in this specific case, suppliers must deliver products with a residual shelf-life equal at least to $80 \%$ of their whole shelf-life. For the sake of simplicity, it is assumed that each item has a shelf-life exactly equal to this value and that no returns are allowed. $T_{\max }$ is the maximum time set for a product's stay within the warehouse, and it is equal to the difference between the shelf-life of the product entering the system $\left(S L_{i n}\right)$ and the shelf-life of the product exiting the system $\left(S L_{\text {out }}\right)$. If $T>T_{\max }$ disposal costs occur.

\subsection{Methodology}

Thanks to an $\mathrm{ABC}$ analysis carried out on the volumes handled in 2019, 5 products were chosen from the A class (out of 289 total items in this class) according to their shelf-life, whose behavior has been simulated.

For each product, an ad hoc spreadsheet was developed under Microsoft Excel ${ }^{\mathrm{TM}}$ using Visual Basic for Applications (VBA) language. Specifically, values of $O P, O U T L, S$ and $S$ for each of the three policy were computed, as a function of the service level $k$. It follows that the total cost depends on the service level which is expected to be ensured to the customers.

In the Re-Order Cycle and $(\mathrm{s}, \mathrm{S})$ policies, TR is strictly bound to the day of the week in which the delivery can take place and the lead time; accordingly, its value was kept constant.

In the following, the solutions obtained will be detailed in terms of costs, together with the cost of the current (AS IS) reorder mechanism.

To be more thorough, a sensitivity analysis was also carried out on the storage cost by varying the cost of holding stocks $(h \in[0 ; 0.5])$, so as to evaluate whether the total cost function can vary according to this parameter.

\section{Results and Discussion}

In this section, results from the simulation will be detailed for each of the five products selected.

\subsection{Purée Preparation}

This product fits the first category presented in section 3 , whose demand is quite steady in time. The shelf-life is 430 days and in line with the aim to guarantee an $S L_{\text {out }}$ of 30 days, the resulting $T_{\max }$ is 400 days. The supplier delivers once per week, with a lead time of 7 days, with a reorder of full pallets.

The best outcome, having set $h=0$, was obtained thanks to the Re-Order Point policy which provides a saving of $5 \%$ compared to the AS IS situation, since it involves a lower number of orders. However, for increasing values of $h$, a $38 \%$ saving occurs when adopting the Re-Order Cycle policy, with a service level of $99 \%$; the reason is the higher frequency of re-order and consequently less stocks. By relaxing the constraint on the number of weekly deliveries, this result is further validated. If for $h=0$ there is no convenience, for greater values each policy tends to reduce the safety stock, improving the inventory performance. Specifically, by assuming three weekly deliveries, $\Delta$ saving compared to the result under the observation of constraints is equal to $34 \%$, against $21 \%$ with two weekly deliveries.

Figure 3 shows the trend of the costs for the three policies. The green line refers to the AS IS management.

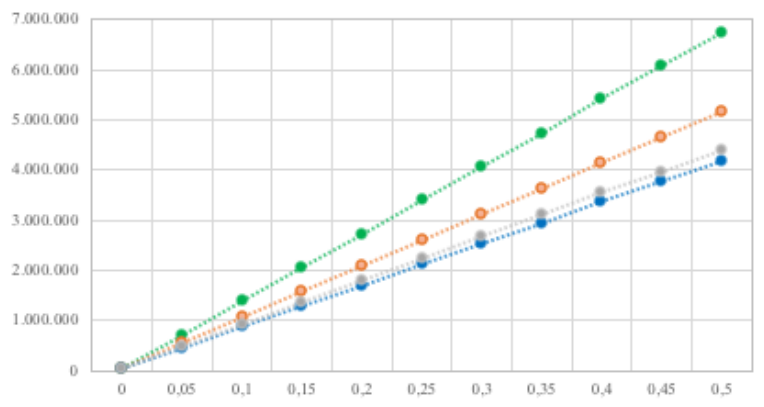

Figure 3. Resulting costs for the three policies implemented for purée preparation (x-axis: $h[\%] ; y$-axis: total costs $[€]$; orange color refers to the Re-Order Point policy, blue to the Re-Order Cycle policy and grey to the $(\mathrm{s} ; \mathrm{S})$ ). 


\subsection{Cod Fillet}

In this case as well, being a frozen product, the shelflife of 186 days does not represent a strict constraint. However, on the contrary compared to the purée preparation, the demand is more variable, presenting peaks in some periods and being almost null in other periods. Two deliveries in a week are provided by the supplier, with a lead time of 2 days. Multiple layers are required.

Re-Order Cycle policy shows a $48 \%$ saving compared to the current management of this product by CIRFOOD. However, in this case, relaxing the constraint on the number of deliveries does not generate relevant outcomes. The reason is the low economic value of the product in question, and to the short lead time of the supplier.

\section{Costs are shown in Figure 4.}

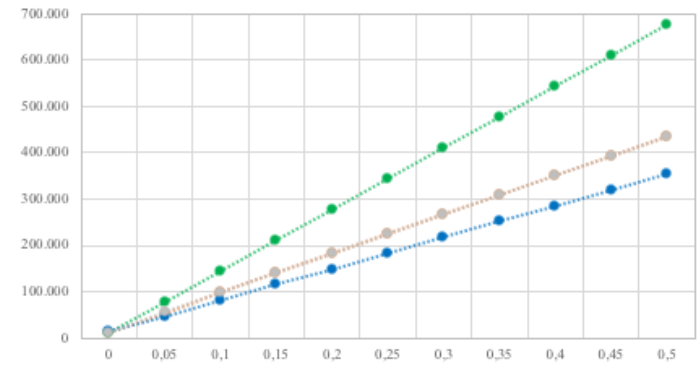

Figure 4. Resulting costs for the three policies implemented for the cod fillet (x-axis: $h[\%]$; $y$-axis: total costs [€]; green color also in this case refers to the company trend, while orange to the Re-Order Point policy, blue to the Re-Order Cycle policy and grey to the $(\mathrm{s} ; \mathrm{S}))$.

\subsection{Dessert}

The demand for this product is obtained by aggregating the single demand of three different flavors. If one flavor is missed, it can be replaced with one of the other two. The behavior is quite irregular, showing a decrease during summer (primarily due to the closure of schools, which own around the $15 \%$ of the overall CIRFOOD business).

This item belongs to the fresh products; despite that, its shelf-life is quite long, i.e. 41 days. The reorder quantity should be at least one pallet (multiple layers) with a lead time of 2 days; no more than 2 deliveries in a week can be performed. Under these conditions, the Re-Order Point policy is definitely not appropriate, since for facing a variable demand it would generate a huge amount of safety stocks and therefore high storage costs. On the contrary, the Re-Order Cycle seems to be more appropriate and allows reaching a saving equal to $18 \%$ as $h$ increases.

By relaxing the constraint of the number of weekly deliveries, once again the Re-Order Cycle shows better performances, allowing to reduce costs up to $23 \%$ simultaneously guaranteeing a service level of $99 \%$ $(k=2.2)$ compared to the scenario with constraints. The reason is the nature of the demand itself: a higher reorder frequency allows to reduce the safety stocks, which otherwise would be particularly high because of such variability.

Figure 5 depicts the costs for the dessert.



Figure 5. Resulting costs for the three policies implemented for the dessert (x-axis: $h[\%]$; y-axis: total costs $[€]$; green color also in this case refers to the company trend, while orange to the Re-Order Point policy, blue to the Re-Order Cycle policy and grey to the $(\mathrm{s} ; \mathrm{S}))$.

\subsection{Biological Yogurt}

Four flavors are available of this specific yogurt, whose management is similar to that of the dessert abovementioned. It is a fresh product, whose $T_{\max }$ is equal to 16 days. The marked demand is highly variable and seasonable (just think that the $53 \%$ of volumes is required by school canteens). From an analysis of the historical data it turned out that stock-out has been sometimes observed for this product; for this reason, a direct comparison between the three policies and the AS IS situation was not possible, having set specific assumptions in the models.

The supplier requires an $\mathrm{AxB}$ reorder, with daily deliveries and the quantity necessarily must be a multiple of the layer.

By observing all the constraints, despite it provides for higher safety stocks $(k=2.7$, but service level $=100 \%)$, the Re-Order Point policy is the best choice, showing a lower value of total costs when $h$ changes. The fact that there is no limit to the number of weekly deliveries allows to schedule orders according to the seasonality of the demand: if during summer only one delivery is necessary (covering 4.3 days), in the remaining period the re-order is more frequent and covers less days (around 1.8).

Results for this product are shown in Figure 6. 


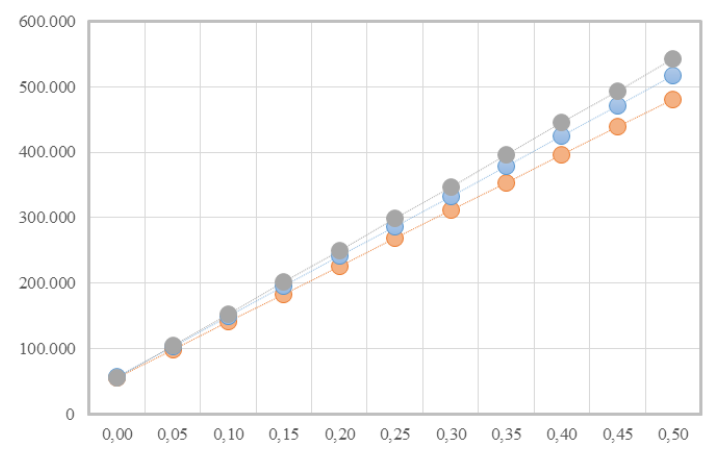

Figure 6. Resulting costs for the three policies implemented for the biological yogurt (x-axis: $h$ [\%]; y-axis: total costs $[€]$; grey color refers to the $(\mathrm{s} ; \mathrm{S})$ policy cost, blue color to the Re-Order Cycle while the red one to the Re-Order policy cost).

\subsection{Crescenza Cheese}

The last product under examination is a fresh cheese with a very short $T_{\max }$ (4 days). The demand is quite irregular, and it gets a significant decrease during summer, when it losses part of its variability; this fact impeded the comparison with the AS IS situation in this case as well, since in some cases stock-out situations have occurred. The reorder must be AxC for multiple packs.

Results confirm that the Re-Order Point policy is the most suitable for a fresh product with reduced shelflife. If the constraint on the number of deliveries is stiffened, only the Re-Order Cycle is appropriate, but results are less satisfactory than those obtained in the circumstances in which constraints are observed.

These last results are depicted in figure 7.

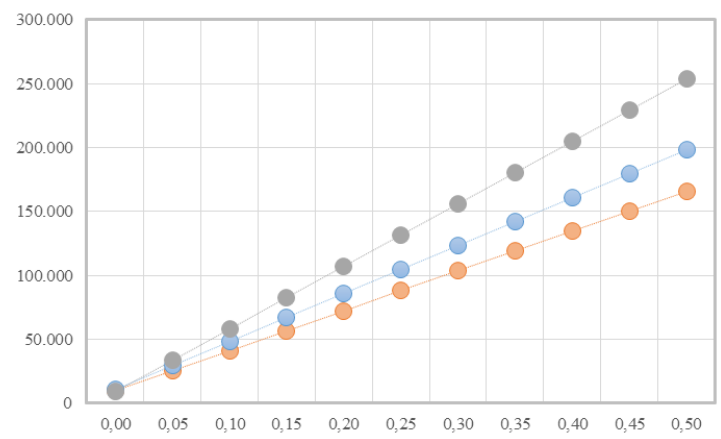

Figure 6. Resulting costs for the three policies implemented for the crescenza cheese (x-axis: $h[\%]$; $y$-axis: total costs $[€]$; grey color refers to the $(\mathrm{s} ; \mathrm{S})$ policy cost, blue color to the Re-Order Cycle while the red one to the Re-Order policy cost).

\section{Conclusions}

Organizations are more and more immersed in highly competitive markets, where demand is increasingly uncertain and variable, due to the changing tastes of consumers. This context forces companies to enhance their flexibility and capability to respond to market demands, at the same time ensuring high quality standards and availability of a wide range of products.
Inventory management is one of the main tools companies can leverage to increase their efficiency and competitiveness on the market, particularly essential in specifically sectors such as the one of perishable food which can be stored only for limited time.

In line with that, this paper aimed at presenting results of a simulation study carried out on five products managed by a company operating in the context of perishable products, servicing the Ho.Re.Ca. channel, with the purpose of identifying the best inventory policy allowing to minimize costs and avoiding stock out and items' deterioration. Three different policies were tested, the Re-Order Point, the $\mathrm{Re}$-Order Level and the $(\mathrm{s}, \mathrm{S})$.

Overall, what emerged is that the $(\mathrm{s}, \mathrm{S})$ policy never returned a satisfactory result, and for this reason it turned out to be the worst in this specific context, when constraints deriving from a shelf-life which characterizes the goods in question occur. The other two, instead, were identified as being more appropriate, specifically for products long-life for which indeed the shelf-life does not represent a stringent constraint. The relaxation of the constraint set by the supplier on the number of weekly deliveries shows that a more frequent reorder can be helpful for keeping under control the stocks level, by reducing the safety stocks and accordingly the storage cost. Moreover, the choice of the best policy is also affected by the nature of the demand of the products; indeed, for instance, in the dessert case the possibility of issuing more orders can reduce the risk of stock out by helping to meet the variability of the demand.

Overall, when $h=0$, the three policies do not differ much from the AS IS situation managed by CIRFOOD in the cases it was possible to make this comparison; when $\mathrm{h}$ tends to increase, instead, the saving is more impactful e.g. for the cod fillet the adoption of the ReOrder Cycle lead to a saving equal to $48 \%$.

This analysis constitutes the bases of a future implementation of an intelligent software able to analyze the different demands and generate order proposals, which is scheduled in the future.

\section{References}

Alrjoub, A.M.S., and Ahmad, M.A. (2017). Inventory management, cost of capital and firm performance: evidence from manufacturing firms in Jordan. Invest. Manag. Financial Innov., 14(3):4-14.

Arnold, T.J.R., (1991). Introduction to Materials Management. New York, Prentice- Hall International Incorporated.

Blackburn, J., and Scudder, G. (2009). Supply chain strategies for perishable products: the case of fresh produce. Prod. Oper. Manag., 18(2): 129-137.

Blankley, A.I., Khouja, M., and Wiggins, C.E. (2008). An Investigation into the Effect of Full-Scale Supply Chain Management Software Adoptions on 
Inventory Balances and Turns. J. Bus. Logist., 29(1):201.

Bottani, E., and Montanari, R. (2010). Supply chain design and cost analysis through simulation. Int. J. of Prod., 48(10): 2859-2886.

Bottani, E., Ferretti, G., Montanari, R., and Vignali, G. (2012). The impact of (S, s) policy on supply network performance: a simulation study. IJBPSCM, 4(2): 164-201.

Bottani, E., Ferretti, G., Montanari, R., and Rinaldi, M. (2014). Analysis and optimization of inventory management policies for perishable food products: a simulation study. Int. J. of Simulat. Process Model., 9(1-2): 16-32.

Chaudhary, V., Kulshrestha, R., and Routroy, S. (2018). State-of-the-art literature review on inventory models for perishable products. J. Adv. in Manag. Res., 15(3): 306-346.

Deniz, B., Scheller-Wolf, A., and Karaesman, I. (2004). Managing Inventories of Perishable Goods: The Effect of Substitution, Working Paper of the Carnegie-Mellon University Pittsburgh. Available at:

http://faculty.fuqua.duke.edu/seminarscalendar/Sc heller-WolfSeminar.pdf

Ferguson, M., Jayaraman, V., and Souza, G.C. (2007). Note: an application of the EOQ model with nonlinear holding cost to inventory management of perishables. Eur. J. Oper. Res., 180(1): 485-490.

Ghare, P.M., and Schrader, G.F. (1963). A model for exponentially decaying inventory. J. of Ind. Eng., 14(5): 238-243.

Goyal, S.K., and Giri, B.C. (2001). Recent trends in modelling of deteriorating inventory. Eur. J. Oper. Res., 134: 1-16.

Goyal, S.K. (1985). Economic order quantity under conditions of permissible delay in payments. J. Oper. Res. Soc., 36(4): 335-338.

Harris, F.W. (1913). How many parts to make at once, Factory, The Magazine of Management, 10 (2):135136.

Iannone, R., Miranda, S., and Riemma, S. (2007). Supply chain distributed simulation: an efficient architecture for multimodel synchronization. Simul. Model. Pract. Th., 15(3): 221-236.

Kolias, G. D., Dimelis, S. P., and Filios, V. P. (2011). An empirical analysis of inventory turnover behaviour in Greek retail sector: 20002005. Int. J. Prod. Econ., 133(1):143-153.

Liu, L., and Lian, Z. (1999). (s, S) continuous review models for products with fixed lifetimes. Oper. Res., 47(1): 150-158.

Longo, F., and Mirabelli, G. (2008). An advanced supply chain management tool based on modeling \& simulation. Comput. Ind. Eng., 54(3): 570-588.

Nahmias, S. (1982). Perishable inventory theory: a review. Oper. Res., 30(3): 680-708.

Pirard, F., Iassinovski, S., and Riane, F. (2011). A simulation based approach for supply network control. Int. J. Prod. Res., 49(24): 7205-7226.

Raafat, F. (1991). Survey of literature on continuously deteriorating inventory models. J. Oper. Res. Soc., 42(1): 27-37.

Rajan, A., Steinberg, R., and Steinberg, R. (1992). Dynamic pricing and ordering decisions by a monopolist. Manag. Sci., 38(2): 240-262.

Ravichandran, N. (1995). Stochastic analysis of a continuous review perishable inventory system with positive lead time and Poisson demand. Eur. J. Oper. Res., 84: 444-457.

Schmidt, C.P., and Nahmias, S. (1985). (S-1,S) policies for perishable inventory. Manag. Sci., 31: 719-728.

Schneider, H., and Ringuest, J.L. (1990). Power approximation for computing (s, S) policies using service level. Manag. Sci., 36: 822-834.

Schwarz, L., and Weng, K.Z. (2000). The design of a JIT supply chain: The effect of lead time uncertainty on safety stock. J. Bus. Logist., 21(2):231-254.

Shapiro, J.F., and Wagner, S.N. (2009). Strategic Inventory Optimization. J. Bus. Logist., 30(2):161173.

Silver, E., 1981. Operations Research in Inventory Management: A review and Critique. University of Calgary, Calgary, Alberta.

Silver, E.A., Naseraldin, H., and Bischak, D.P. (2009). Determining the reorder point and order-up-tolevel in a periodic review system so as to achieve a desired fill rate and a desired average time between replenishments. J. Oper. Res. Soc., 60(9): 12441253.

Van Der Vorst, J.G.A.J. (2000). Effective food supply chains: generating, modelling and evaluating supply chain scenarios. $\mathrm{PhD}$ thesis, Wageningen University \& Research, Wageningen. Available at: https://library.wur.nl/WebQuery/wurpubs/66572

Waller, M., Johnson, M. E., and Davis, T. (1999). Vendor-managed inventory in the retail supply chain. J. Bus. Logist., 20:183-204.

Wang, K.-J., Lin, Y.S., and Jonas, C.P. (2011). Optimizing inventory policy for products with time-sensitive deteriorating rates in a multi-echelon supply chain. Int. J. Prod. Eco., 130(1): 66-76.

Wang, X., and Li, D. (2012). A dynamic product quality evaluation based pricing model for perishable food supply chains. Omega, 40: 906-917.

Waters, D. (2003). Logistics: An Introduction to Supply Chain Management. Palgrave MacMillan, New York. 
Weiss, H.J. (1980). Optimal ordering policies for continuous review perishable inventory models. Oper. Res., 28(2): 365-374

Whitin, T.M. (1957). Theory of Inventory Management, Princeton University Press, Princeton, NJ.

Yu, M. \& Nagurney, A. (2013). Competitive food supply chain networks with application to fresh produce. Eur. J. Oper.Res., 224(2): 273-282. 